Article

\title{
Exome Evaluation of Autism-Associated Genes in Amazon American Populations
}

\author{
Giovana E. da Costa ${ }^{1}$, Giordane L. Fernandes ${ }^{1}$, Juliana C. G. Rodrigues ${ }^{1}{ }^{(D)}$, Diana F. da V. B. Leal ${ }^{1}(\mathbb{D}$,

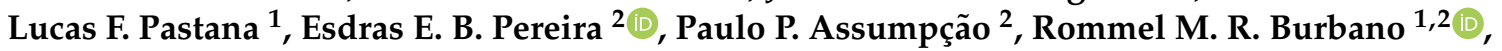 \\ Sidney E. B. dos Santos ${ }^{1,2}$, João F. Guerreiro ${ }^{2} \mathbb{C}$, Marianne R. Fernandes ${ }^{1, *}$ and Ney P. C. dos Santos ${ }^{1,2}$ \\ 1 Núcleo de Pesquisas em Oncologia, Universidade Federal do Pará, Belém 66075-110, Brazil; \\ giovanaescribano@hotmail.com (G.E.d.C.); giordanelages@hotmail.com (G.L.F.); \\ julianacgrodrigues@gmail.com (J.C.G.R.); dianafeio@hotmail.com (D.F.d.V.B.L.); \\ lucas.pastana@ics.ufpa.br (L.F.P.); rommelburbano@gmail.com (R.M.R.B.); sidneysantos@ufpa.br (S.E.B.d.S.); \\ npcsantos.ufpa@gmail.com (N.P.C.d.S.) \\ 2 Laboratório de Genética Humana e Médica, Instituto de Ciências Biológicas, Universidade Federal do Pará, \\ Belém 66075-110, Brazil; esdrasedgarbp@gmail.com (E.E.B.P.); assumpcaopp@gmail.com (P.P.A.); \\ joao.guerreiro53@gmail.com (J.F.G.) \\ * Correspondence: fernandesmr@yahoo.com.br
}

Citation: da Costa, G.E.; Fernandes, G.L.; Rodrigues, J.C.G.; da V. B. Leal, D.F.; Pastana, L.F.; Pereira, E.E.B.; Assumpção, P.P.; Burbano, R.M.R.; dos Santos, S.E.B.; Guerreiro, J.F.; et al. Exome Evaluation of Autism-Associated Genes in Amazon American Populations. Genes 2022, 13, 368. https://doi.org/10.3390/ genes13020368

Academic Editors: Kun Xia, Jinchen Li and Hui Guo

Received: 22 December 2021

Accepted: 19 January 2022

Published: 18 February 2022

Publisher's Note: MDPI stays neutral with regard to jurisdictional claims in published maps and institutional affiliations.

Copyright: (c) 2022 by the authors. Licensee MDPI, Basel, Switzerland. This article is an open access article distributed under the terms and conditions of the Creative Commons Attribution (CC BY) license (https:// creativecommons.org/licenses/by/ $4.0 /)$.

\begin{abstract}
Autism spectrum disorder is a neurodevelopmental disorder, affecting one in 160 children worldwide. The causes of autism are still poorly understood, but research shows the relevance of genetic factors in its pathophysiology, including the CHD8, SCN2A, FOXP1 and SYNGAP1 genes. Information about the genetic influence on various diseases, including autism, in the Amerindian population from Amazon, is still scarce. We investigated 35 variants of the CHD8, SCN2A, FOXP1, and SYNGAP1 gene in Amazonian Amerindians in comparison with publicly available population frequencies from the 1000 Genomes Project database. Our study identified 16 variants in the Amerindian population of the Amazon with frequencies significantly different from the other populations. Among them, the SCN2A (rs17183814, rs75109281, and rs150453735), FOXP1 (rs56850311 and rs939845), and SYNGAP1 (rs9394145 and rs115441992) variants presented higher frequency than all other populations analyzed. In addition, nine variants were found with lower frequency among the Amerindians: CHD8 (rs35057134 and rs10467770), SCN2A (rs3769951, rs2304014, rs1838846, and rs7593568), FOXP1 (rs112773801 and rs56850311), and SYNGAP1 (rs453590). These data show the unique genetic profile of the indigenous population of the Brazilian Amazon. Knowledge of these variants can help to understand the pathophysiology and diagnosis of autism among Amerindians, Brazilians, and in admixed populations that have contributions from this ethnic group.
\end{abstract}

Keywords: autism; susceptibility; genetic; Amerindians

\section{Introduction}

Autism spectrum disorder (ASD) is one of the main neuropsychiatric conditions and is characterized by different behavioral manifestations, including deficits in social communication and interaction, repetitive patterns of behavior, interests, and performance in specific activities [1]. The World Health Organization estimates that one in every 160 children is identified with ASD, being approximately 70 million people with ASD worldwide. In Brazil, it is estimated that 2 million people have ASD (1\%) $[2,3]$.

According to the Brazilian Institute of Geography and Statistics (IBGE), the Amerindian population is estimated at 896,917 individuals, representing $0.47 \%$ of the Brazilian population [4]. Studies about ASD in Amerindian populations are rare. In other countries, such as Australia, Amerindian Australians with the autism spectrum are twice as likely to have a severe or profound form of ASD and may have worse long-term outcomes compared to 
non-Amerindian Australians with the same condition. It was reported that Amerindians had less support and access to services in health and medicines [5].

ASD was discovered by Kanner in 1943 in the U.S. and by Asperger in 1944 in Vienna $[6,7]$. Currently, the causes of autism are still not well understood, although environmental, non-genetic, and genetic factors contribute to the disease. Bai et al. evaluated the contribution of various genetic and non-genetic factors to ASD risk. Researchers estimated heritability with maternal effects and shared and nonshared environments on ASD risk, including more than 2 million individuals from 5 countries. This study results reported significant evidence that most of the risk for ASD came from genetic factors $[8,9]$.

In the largest genetic sequencing study of autism spectrum disorder (ASD) to date, researchers identified 102 genes related to the risk of ASD. The study enrolled 35,584 participant samples, including nearly 11,986 with ASD. Allelic variations in the 102 genes were related to susceptibility to neurodevelopmental disorders, such as ASD, and were able to differentiate this condition from other general neurodevelopmental disorders [10]. However, the impact of genetic factors associated with ASD in the Amazonian Amerindian is still unknown.

This is the first genetic study based on single-nucleotide polymorphisms (SNPs) associated with ASD in Amerindians from the Brazilian Amazon. This study characterizes the molecular profile of four of 102 genes related to ASD from a study by Satterstrom et al. [10] by analyzing the exome of Amerindian individuals from the Brazilian Amazon. The objective was to describe SNPs that may explain the predisposition to the development of ASD in Amazonian Amerindian and compare them with the worldwide population.

\section{Materials and Methods}

\subsection{Study and Reference Populations}

The Indigenous group (IND) was composed of non-related 64 Amerindians which represent 12 Amazonian ethnic groups of Northern Brazil: (i) Asurini do Xingu ( $\mathrm{N}=5$ ), (ii) Arara $(\mathrm{N}=7)$, (iii) Araweté $(\mathrm{N}=6)$, (iv) Asurini from Tocantins $(\mathrm{N}=16)$, (v) Awa-Guajá $(\mathrm{N}=8)$, (vi) Kayapó/Xikrin ( $\mathrm{N}=2)$, (vii) Zo'é ( $\mathrm{N}=5)$, (viii) Wajãpi $(\mathrm{N}=10)$, (ix) Karipuna $(\mathrm{N}=1),(\mathrm{x})$ Phurere $(\mathrm{N}=1),(\mathrm{xi})$ Munduruku $(\mathrm{N}=1)$, and (xii) Juruna $(\mathrm{N}=2)$.

All participants of the study and their ethnic group leaders signed a free-informed consent. The study was approved by the National Research Ethics Committee (CONEP) and the Research Ethics Committee of the Tropical Medicine Center of the Federal University of Pará, under CAAE number 20654313.6.0000.5172. The period for recruiting participants was from September 2017 to December 2018.

The results were compared with genomic data from populations from other countries available in the phase 3 version of the 1000 Genomes Database [11]. These populations included 661 Africans (AFR), 347 Americans (AMR), 504 from East Asia (EAS), 503 from Europe (EUR), and 489 from South Asia (SAS).

\subsection{Extraction of the DNA and Preparation of the Exome Library}

DNA extraction was performed using the phenol-chloroform method described by Sambrook et al. [12]. The quantification and integrity of the genetic material were analyzed by a Nanodrop-8000 spectrophotometer (Thermo Fisher Scientific Inc., Wilmington, DE, USA) and $2 \%$ agarose gel electrophoresis, respectively.

Exome libraries were prepared using the Nextera Rapid Capture Exome (Illumina ${ }^{\circledR}$, San Diego, CA, USA) and SureSelect Human All Exon V6 (Agilent) kits. The sequencing reactions were performed on the NextSeq $500^{\circledR}$ platform (Illumina ${ }^{\circledR}$, San Diego, CA, USA) using the NextSeq 500 High-output v2 300 cycle kit (Illumina ${ }^{\circledR}$, San Diego, CA, USA).

\subsection{Bioinformatics Analysis}

Bioinformatics analysis was performed as previously described by Rodrigues et al. [13]. 


\subsection{Statistical Analysis}

Allele frequencies of the IND populations were obtained by gene counting compared to the other study populations (AFR, EUR, AMR, EAS, and SAS). Fisher's test was used to compare frequency differences between populations. A $p$-value $<0.05$ was considered statistically significant. Interpopulation variability of polymorphisms was assessed using the Wright fixation index (FST). Data analyses were performed using RStudio version 3.5.1.

\subsection{Selection of Genes and Variants}

The selection of genes was based in the results pointed out in the study of Satterstrom et al. [10]. Four of these genes, CHD8, SCN2A, FOXP1, and SYNGAP1, were classified as risk genes with the lowest rates of "false discovery rate (FDR)" and "familywise error Rate (FWER)".

The SNP inclusion criteria were: (i) minimum of 10 reeds of coverage (fastx_tools v.0.13 http:/ /hannonlab.cshl.edu/fastx_toolkit/, accessed on October 2021); (ii) variant impact: modifier, moderate or high (SNPeff classification (https://pcingola.github.io/SnpEff/, accessed on October 2021); and (iii) allelic and genomic frequency in worldwide populations (http:/ / www.1000genomes.org, accessed on October 2021).

\section{Results}

A total of 59 genetics variants were identified in CHD8, SCN2A, FOXP1, and SYNGAP1 (Supplementary Table S1). Thirty-five of 59 variants met the SNP inclusion criteria. Eight variants were identified in the CHD8 gene, eleven in $S C N 2 A$, twelve in FOXP1, and four in SYNGAP1 in the individuals analyzed. Table 1 shows characteristics of these variants, including their reference number, chromosome region, nucleotide exchange, impact predicted by the SNPeff software, and the allele frequency referring to the indigenous group (IND) and the five continental populations present in the 1000 Genomes Program (AFR, AMR, EAS, EUR, and SAS) [11]. Among the selected polymorphisms, thirty have predicted impact as a modifier and five as moderate. Twenty-eight are from the intronic region, five from the CDS region, and two from the $3^{\prime} \mathrm{UTR}$ region. The frequencies of 35 variants were compared with different population groups (Table 2).

Among the 35 variants, 16 variants showed frequencies among Amerindians significantly different from all other populations. Seven variants with greater frequency among Amerindians: SCN2A (rs17183814, rs75109281, and rs150453735), FOXP1 (rs939845 and rs2037474), and SYNGAP1 (rs115441992 and rs9394145). Nine variants with lower frequency among the Amerindians: CHD8 (rs35057134 and rs10467770), SCN2A (rs3769951, rs2304014, rs1838846, and rs7593568), FOXP1 (rs112773801 and rs56850311), and SYNGAP1 (rs453590).

The EUR and SAS populations stand out as those with the most variants with significant differences for the Amerindian population $(p<0.05)$. For the EUR population, five were in the CHD8 gene (rs35057134, rs10467770, rs111776414, rs1998332, and rs149307240), nine in the SCN2A gene (rs17183814, rs75109281, rs3769951, rs28472553, rs139906774, rs2304014, rs150453735, rs1838846, and rs7593568), seven in the FOXP1 gene (rs112773801, rs58847217, rs72960080, rs13068094, rs56850311, rs939845, and rs2037474), and four in SYNGAP1 (rs76557362, rs453590, rs115441992, and rs9394145).

For SAS, four were in the CHD8 gene (rs35057134, rs10467770, rs1998332, and rs149307240), nine were in the SCN2A gene (rs17183814, rs75109281, rs3769951, rs28472553, rs139906774, rs2304014, rs150453735, rs1838846, and rs7593568), eight in FOXP1 (rs112773801, rs58847217, rs72960080, rs13068094, rs56850311, rs939845, rs2037474, and rs15101125) and four in SYNGAP1 (rs76557362, rs453590, rs115441992, and rs9394145).

In relation to the AFR population, five polymorphisms were found to be significantly divergent in the CHD8 gene (rs35057134, rs10467770, rs57764234, rs111776414, and rs149307240), eight in the SCN2A gene (rs17183814, rs75109281, rs3769951, rs2304014, rs150453735, rs1867864, rs1838846, and rs7593568), four in FOXP1 (rs112773801, rs56850311, rs939845, and rs2037474), and four in the SYNGAP1 gene (rs76557362, rs453590, rs115441992, 
and rs9394145), adding up to a total of twenty-one significantly different variants of the IND population.

The AMR population presented twenty-two statistically different polymorphisms in relation to the IND population: three in the CHD8 gene (rs35057134, rs10467770, and rs1998332), nine in the SCN2A gene (rs17183814, rs75109281, rs3769951, rs28472553, rs139906774, rs2304014, rs150453735, rs1838846, and rs7593568), six in the FOXP1 gene (rs112773801, rs72960080, rs13068094, rs568503111, rs939845, and rs2037474), and four in SYNGAP1 (rs76557362, rs453590, rs115441992, and rs9394145).

Table 1. Description of variants in the CHD8, SCN2A, FOXP1, and SYNGAP1 genes in the Indigenous group and continental populations (African, American, East Asia, European, and South Asia) described in the 1000 Genomes Project.

\begin{tabular}{|c|c|c|c|c|c|c|c|c|c|c|}
\hline Gene & SNP ID & Region & Alleles & $\begin{array}{l}\text { Impact Predicted } \\
\text { by SNPeff }\end{array}$ & IND & AFR & AMR & EAS & EUR & SAS \\
\hline CHD8 & rs35057134 & Intronic & $G A>G$ & Modifier & 0.0143 & 0.2250 & 0.2070 & 0.3480 & 0.2740 & 0.2550 \\
\hline CHD8 & rs80311097 & Intronic & $\mathrm{C}>\mathrm{A}$ & Modifier & 0.0000 & 0.0610 & 0.0010 & 0.0000 & 0.0010 & 0.0000 \\
\hline CHD8 & rs10467770 & CDS & $\mathrm{C}>\mathrm{T}$ & Moderate & 0.0781 & 0.2240 & 0.1900 & 0.3450 & 0.2450 & 0.2490 \\
\hline CHD8 & rs111250264 & CDS & $G>A$ & Moderate & 0.0086 & 0.0050 & 0.0000 & 0.0000 & 0.0000 & 0.0000 \\
\hline CHD8 & rs57764234 & Intronic & $\mathrm{C}>\mathrm{T}$ & Modifier & 0.0246 & 0.3160 & 0.0290 & 0.0000 & 0.0210 & 0.0050 \\
\hline CHD8 & rs111776414 & Intronic & $\mathrm{G}>\mathrm{GA}$ & Modifier & 0.0417 & 0.1610 & 0.0120 & 0.0010 & 0.0020 & 0.0110 \\
\hline CHD8 & rs1998332 & Intronic & $\mathrm{G}>\mathrm{A}$ & Modifier & 0.6172 & 0.5730 & 0.7780 & 0.8880 & 0.9060 & 0.9170 \\
\hline CHD8 & rs149307240 & CDS & $\mathrm{C}>\mathrm{T}$ & Moderate & 0.0259 & 0.0000 & 0.0160 & 0.0000 & 0.0010 & 0.0000 \\
\hline$S C N 2 A$ & rs17183814 & CDS & $\mathrm{G}>\mathrm{A}$ & Moderate & 0.2500 & 0.0210 & 0.0820 & 0.1380 & 0.0570 & 0.1420 \\
\hline$S C N 2 A$ & rs75109281 & Intronic & $\mathrm{C}>\mathrm{T}$ & Modifier & 0.0833 & 0.0120 & 0.0030 & 0.0000 & 0.0000 & 0.0000 \\
\hline$S C N 2 A$ & rs3769951 & Intronic & $\mathrm{C}>\mathrm{T}$ & Modifier & 0.0135 & 0.1640 & 0.2480 & 0.2610 & 0.2920 & 0.3310 \\
\hline$S C N 2 A$ & rs28472553 & Intronic & $A>C$ & Modifier & 0.0833 & 0.0290 & 0.0030 & 0.0000 & 0.0010 & 0.0000 \\
\hline$S C N 2 A$ & rs139906774 & Intronic & $\mathrm{G}>\mathrm{GA}$ & Modifier & 0.0000 & 0.0520 & 0.3000 & 0.3420 & 0.2420 & 0.1860 \\
\hline$S C N 2 A$ & rs2304014 & Intronic & $\mathrm{T}>\mathrm{A}$ & Modifier & 0.0270 & 0.2280 & 0.1330 & 0.1410 & 0.1760 & 0.1390 \\
\hline$S C N 2 A$ & rs6432821 & Intronic & $\mathrm{T}>\mathrm{C}$ & Modifier & 1.0000 & 0.9520 & 0.9970 & 1.0000 & 1.0000 & 0.9990 \\
\hline$S C N 2 A$ & rs150453735 & Intronic & $\mathrm{C}>\mathrm{T}$ & Modifier & 0.1852 & 0.0020 & 0.0530 & 0.0000 & 0.0000 & 0.0000 \\
\hline$S C N 2 A$ & rs1867864 & Intronic & $\mathrm{C}>\mathrm{T}$ & Modifier & 0.4453 & 0.6130 & 0.4600 & 0.3430 & 0.5640 & 0.4870 \\
\hline$S C N 2 A$ & rs1838846 & Intronic & $A>G$ & Modifier & 0.0000 & 0.7930 & 0.7940 & 0.7430 & 0.8300 & 0.6980 \\
\hline$S C N 2 A$ & rs7593568 & Intronic & $A>G$ & Modifier & 0.0000 & 0.7950 & 0.7950 & 0.7430 & 0.8300 & 0.6950 \\
\hline FOXP1 & rs1435680522 & & $\mathrm{GT}>\mathrm{G}$ & & & & & & & 0.0000 \\
\hline FOXP1 & rs112773801 & 3UTR & $\mathrm{G}>\mathrm{GT}$ & Modifier & 0.0167 & 0.4240 & 0.1860 & 0.4510 & 0.1340 & 0.3290 \\
\hline FOXP1 & rs58847217 & Intronic & $\mathrm{T}>\mathrm{C}$ & Modifier & 0.0278 & 0.1010 & 0.0040 & 0.0000 & 0.0000 & 0.0000 \\
\hline FOXP1 & rs76145927 & CDS & $\mathrm{T}>\mathrm{C}$ & Moderate & 0.0000 & 0.0000 & 0.0060 & 0.0390 & 0.0030 & 0.0000 \\
\hline FOXP1 & rs72960080 & Intronic & $\mathrm{T}>\mathrm{C}$ & Modifier & 0.0833 & 0.1190 & 0.0040 & 0.0000 & 0.0000 & 0.0000 \\
\hline FOXP1 & rs13068094 & Intronic & $\mathrm{C}>\mathrm{T}$ & Modifier & 0.0833 & 0.1040 & 0.5400 & 0.0550 & 0.5750 & 0.2820 \\
\hline FOXP1 & rs7638391 & Intronic & $\mathrm{G}>\mathrm{T}$ & Modifier & 1.0000 & 0.9970 & 0.9650 & 1.0000 & 0.9230 & 0.9780 \\
\hline FOXP1 & rs56850311 & Intronic & $\mathrm{A}>\mathrm{T}$ & Modifier & 0.0000 & 0.3960 & 0.2520 & 0.1060 & 0.2890 & 0.2230 \\
\hline FOXP1 & rs7639736 & Intronic & $C>A$ & Modifier & 0.0000 & 0.0760 & 0.0560 & 0.0730 & 0.0130 & 0.0200 \\
\hline FOXP1 & rs939845 & Intronic & $A>G$ & Modifier & 0.3984 & 0.1630 & 0.2250 & 0.1110 & 0.0640 & 0.0440 \\
\hline FOXP1 & rs2037474 & Intronic & $A>G$ & Modifier & 0.5156 & 0.2720 & 0.3430 & 0.4360 & 0.1360 & 0.2450 \\
\hline FOXP1 & rs151011253 & Intronic & $\mathrm{T}>\mathrm{TA}$ & Modifier & 0.0139 & 0.0850 & 0.0560 & 0.0310 & 0.0540 & 0.0960 \\
\hline SYNGAP1 & rs76557362 & Intronic & $\mathrm{C}>\mathrm{T}$ & Modifier & 0.0833 & 0.2530 & 0.0130 & 0.0000 & 0.0000 & 0.0000 \\
\hline SYNGAP1 & rs453590 & Intronic & $\mathrm{C}>\mathrm{T}$ & Modifier & 0.0000 & 0.2700 & 0.4060 & 0.6410 & 0.3860 & 0.5430 \\
\hline SYNGAP1 & rs115441992 & Intronic & $\mathrm{C}>\mathrm{T}$ & Modifier & 0.0833 & 0.0140 & 0.0090 & 0.0000 & 0.0130 & 0.0020 \\
\hline SYNGAP1 & rs9394145 & Intronic & $\mathrm{C}>\mathrm{T}$ & Modifier & 0.5078 & 0.0130 & 0.3240 & 0.2500 & 0.3150 & 0.3220 \\
\hline
\end{tabular}


Table 2. Comparison between the allelic frequency of the Indigenous population and continental populations (African, American, East Asia, European, and South Asia) described in the database of 1000 Genomes Project.

\begin{tabular}{|c|c|c|c|c|c|c|}
\hline Gene & DbSNP & IND vs. AFR * & IND vs. AMR * & IND vs. EAS * & IND vs. EUR * & IND vs. SAS * \\
\hline CHD8 & rs35057134 & $5.98 \times 10^{-6}$ & $2.74 \times 10^{-5}$ & $5.31 \times 10^{-10}$ & $1.39 \times 10^{-7}$ & $7.66 \times 10^{-7}$ \\
\hline CHD8 & rs80311097 & 0.24887 & 0.28751 & 0.21283 & 0.21318 & 0.21826 \\
\hline CHD8 & rs10467770 & 0.00572 & 0.03028 & $2.97 \times 10^{-6}$ & 0.00220 & 0.00138 \\
\hline CHD8 & rs111250264 & 0.30959 & 0.28751 & 0.21283 & 0.21318 & 0.21826 \\
\hline CHD8 & rs57764234 & $6.46 \times 10^{-8}$ & 1.00000 & 0.03481 & 0.64915 & 0.06785 \\
\hline CHD8 & rs111776414 & 0.01566 & 0.07929 & 0.00504 & 0.00507 & 0.05415 \\
\hline CHD8 & rs1998332 & 0.50781 & 0.01151 & $4.40 \times 10^{-7}$ & $3.06 \times 10^{-8}$ & $6.23 \times 10^{-9}$ \\
\hline CHD8 & rs149307240 & 0.02173 & 0.36125 & 0.03481 & 0.03493 & 0.03665 \\
\hline SCN2A & rs17183814 & $1.19 \times 10^{-10}$ & 0.00026 & 0.02585 & $5.70 \times 10^{-6}$ & 0.04046 \\
\hline$S C N 2 A$ & rs75109281 & 0.00339 & 0.00042 & $8.63 \times 10^{-5}$ & $8.70 \times 10^{-5}$ & $9.84 \times 10^{-5}$ \\
\hline SCN2A & rs3769951 & 0.00037 & $1.60 \times 10^{-6}$ & $4.39 \times 10^{-7}$ & $3.69 \times 10^{-8}$ & $2.16 \times 10^{-9}$ \\
\hline$S C N 2 A$ & rs28472553 & 0.05210 & 0.00042 & $8.63 \times 10^{-5}$ & $8.70 \times 10^{-5}$ & $9.84 \times 10^{-5}$ \\
\hline$S C N 2 A$ & rs139906774 & 0.35386 & $3.54 \times 10^{-8}$ & $6.13 \times 10^{-10}$ & $1.54 \times 10^{-6}$ & 0.00011 \\
\hline$S C N 2 A$ & rs2304014 & $3.85 \times 10^{-5}$ & 0.01857 & 0.00941 & 0.00166 & 0.01459 \\
\hline$S C N 2 A$ & rs 6432821 & 0.10268 & 1.00000 & 1.00000 & 1.00000 & 1.00000 \\
\hline SCN $2 A$ & rs150453735 & $9.91 \times 10^{-13}$ & 0.00066 & $1.86 \times 10^{-11}$ & $1.90 \times 10^{-11}$ & $2.57 \times 10^{-11}$ \\
\hline$S C N 2 A$ & rs1867864 & 0.01590 & 1.00000 & 0.09628 & 0.10907 & 0.69027 \\
\hline$S C N 2 A$ & rs1838846 & $8.09 \times 10^{-38}$ & $3.83 \times 10^{-35}$ & $5.39 \times 10^{-32}$ & $1.00 \times 10^{-40}$ & $2.50 \times 10^{-28}$ \\
\hline$S C N 2 A$ & rs7593568 & $5.55 \times 10^{-38}$ & $3.83 \times 10^{-35}$ & $5.39 \times 10^{-32}$ & $1.00 \times 10^{-40}$ & $3.54 \times 10^{-28}$ \\
\hline FOXP1 & rs1435680522 & 0.16887 & 0.28751 & 0.21283 & 0.21318 & 0.21826 \\
\hline FOXP1 & rs112773801 & $2.15 \times 10^{-13}$ & 0.00013 & $3.53 \times 10^{-14}$ & 0.00344 & $2.18 \times 10^{-9}$ \\
\hline FOXP1 & rs58847217 & 0.07415 & 0.06453 & 0.03481 & 0.03493 & 0.03665 \\
\hline FOXP1 & rs76145927 & 0.16887 & 0.39900 & 0.49517 & 0.30231 & 0.21827 \\
\hline
\end{tabular}

IND. Indigenous; AFR. African; AMR. American, EAS. East Asia; EUR. European; SAS. South Asia; SAS. CDS coding sequence. *. Fisher's exact test.

The EAS population showed six statistically different variants in the CHD8 gene (rs35057134, rs10467770, rs57764234, rs111776414, rs1998332, and rs149307240), nine in the SCN2A gene (rs17183814, rs75109281 rs3769951, rs28472553, rs139906774, rs2304014, rs150453735, rs1838846, and rs7593568), five in the FOXP1 gene (rs112773801, rs58847217, rs72960080, rs56850311, and rs939845), and four in the SYNGAP1 gene (rs76557362, rs453590, rs115441992, and rs9394145), summing twenty-four polymorphisms.

The rs35057134 (CHD8) had a low frequency in the Amerindian group, with differences greater than $20 \%$ of that found in the world population, as well as the rs10467770 (CHD8), rs3769951 (SCN2A), rs2304014 (SCN2A), and rs112773801 (FOXP1). Otherwise, the rs17183814 (SCN2A) variant presented higher frequencies in the Amerindian population, in contrast to those found in the world populations, except for EAS. This frequency pattern is also observed in the rs9394145 (FOXP1), which shows higher frequencies in Amazonian Amerindians.

Multidimensional scale analysis (MDS), using FST values (Supplementary Table S2) for the 35 variants in the CHD8, SCN2A, FOXP1, and SYNGAP1 genes revealed the existence of four major groups (Figure 1): The African population (AFR) is completely isolated, showing greater genetic diversity, as well as the American population (AMR); European (EUR), East Asian (EAS), and South Asian (SAS) populations clustered in the lower center; and the Indigenous group (IND) in the lower left corner. This analysis reported that the Amazonian population distances itself from other world populations concerning the variants analyzed for ASD susceptibility. The populations diverged significantly from African populations and showed greater proximity with populations from South and East Asia, compared to populations of European and, even, Latin American peoples. 


\section{Continental populations}

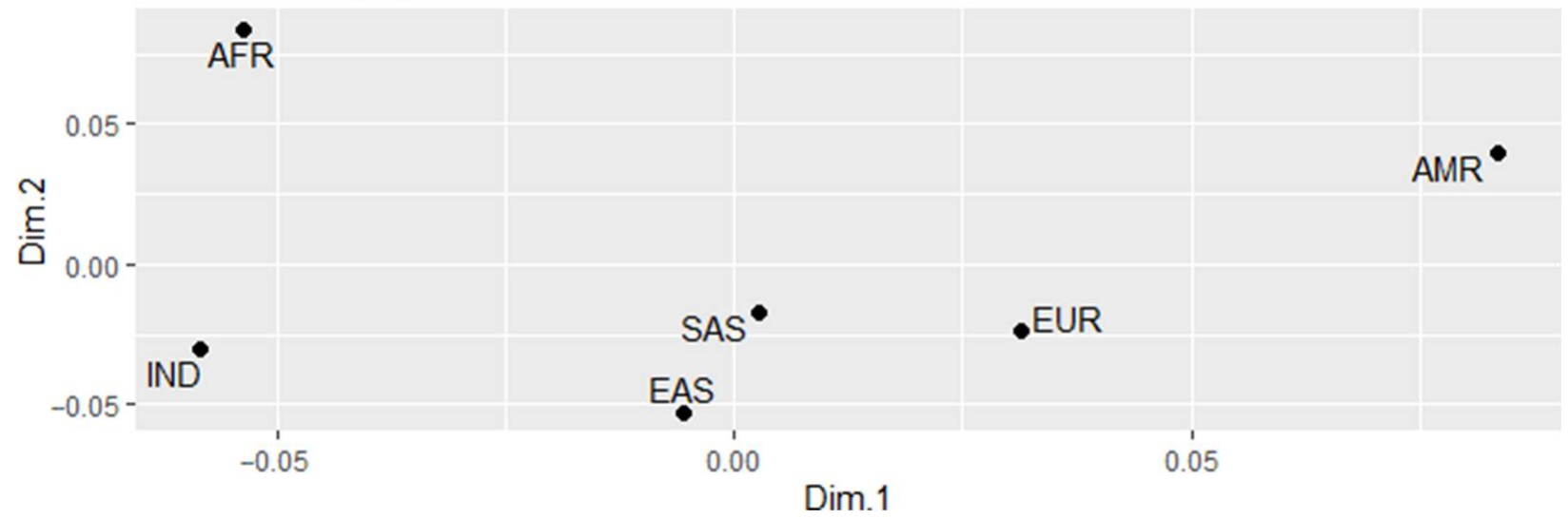

Figure 1. Multidimensional scale graph illustrating the ethnic populations grouping according to the genetic profile of the 35 variants in the CHD8, SCN2A, FOXP1, and SYNGAP1 genes.

\section{Discussion}

Previous evidence suggests ASD is modulated by genetic factors, such as SNPs. However, it is unclear which genes or SNPs contribute significantly to autism. A large genetic sequencing report showed 102 genes associated with the risk of autism [10]. In this study, we selected four genes from this previous study. We identified and characterized candidate SNPs in these selected genes associated with ASD, which have not been studied in Amazonian Amerindians. We also compared these data with worldwide populations. We hypothesize that SNPs in CHD8, SCN2A, FOXP1, and SYNGAP1 genes could predispose an individual to ASD, especially those with a greater contribution of Amerindian ancestry.

The influence of ancestry difference in the autism spectrum disorder is limited. Population-based studies of the prevalence of autism spectrum disorder (ASD) in the United States have reported no differences among selected racial and ethnic groups, however without analyzing other ethnicities, such as native people [14].

There is still a lack of research investigating this issue, especially in Brazil. The Brazilian population has an admixture population characterized by a tetra-hybrid ancestry with European, African, American, and Asian composition [15]. Besides few genetic studies related to ASD in Brazil, there are no studies on this subject in Amerindians.

A previous study by Shochet et al. [16] had shown that Indigenous with ASD people living in remote areas had limited access to healthcare services. This is due to cultural and linguistic differences that are potential barriers to the diagnosis and treatment of this condition among the Amerindian population. Besides, some clinical features, such as avoiding eye contact and social communication, were not considered problematic in Amerindian cultures [17].

Current studies showed heritability of ASD was estimated to be approximately 50 to $80 \%$, indicating that the variation in ASD occurrence in the population was mostly owing to inherited genetic influences [8,18]. Satterstrom and collaborators have identified 102 ASD risk genes in a large-scale genetic analysis to date. These genes, including CHD8, $S C N 2 A, F O X P 1$, and SYNGAP1, regulate the development and function of the human brain [10].

The present study is the first to investigate the CHD8, SCN2A, FOXP1, and SYNGAP1 genes in Amazonian Amerindians and highly admixed population in the Amazon region of Brazil with a major Amerindian component. The Amerindian ancestral contribution in the Brazilian population is $17 \%$, except in the Amazon region which increases up to approximately 30\%. In this area, the Amerindian ancestry population has the highest contribution in the country $[18,19]$.

Besides the SCN2A, FOXP1, and SYNGAP1 genes, CHD8 variants are among the most replicated and common findings in ASD genetic studies. They are associated with the most 
common form of autism spectrum disorder, classic autism, along with macrocephaly, distinct dysmorphic facial features, and gastrointestinal disturbance [20,21]. Genetic variants in the SCN2A gene are also important in ASD; they can play a significant role in psychiatric disorders. They were associated with childhood seizures, epileptic encephalopathy, epileptic syndromes, as well as intellectual disability, and ASD without epilepsy [22,23].

The FOXP1 gene has been implicated in neurodevelopmental disorders, such as ASD, and the FOXP1 syndrome, in individuals with the presence of autistic spectrum disorder traits, intellectual disability, language impairment, and psychiatric characteristics [24,25]. In addition, the SYNGAP1 gene is associated with several neurodevelopmental disorders, including non-syndromic intellectual disability and ASD, with symptoms that include encephalopathy, epilepsy, hypotonia, stereotyped behaviors, and aggression [23].

Of 59 variants found in the exome analysis made of the CHD8, SCN2A, FOXP1, and SYNGAP1 genes, 35 variants could potentially be associated with the development of autistic spectrum disorder. Among the investigated variants, five of them had a moderate impact. They were all classified as CDS (coding sequence) and 30 variants had a modifier impact, 28 were intronic, and 2 were in the $3^{\prime}$ UTR region.

In the present study, we compared the genetic variability of Amerindian populations from the Amazon region with five populations from the 1000 Genomes Project [11]. Our results about the comparison between ethnic groups revealed that the AFR group were isolated, with the greatest genetic difference from the AMR. This finding is consistent with the history of human populations in the world, in which the Amerindian and African groups represent the extremes of the evolutionary process [26].

Still, regarding the comparative results between ethnic groups, the lowest values of genetic differences with Amazonian Amerindians were observed in the population of East Asia $($ FST value $=0.00219)$. This result corroborates the hypothesis of the "Bering Strait", an extension of land that joined Northeast Asia and North America [27].

The distancing of the IND and AMR groups was not expected (FST value $=0.07114$ ); however, this analysis was only evaluated in the variants found for the investigated genes. The sample of the American population of the 1000 Genomes Project includes several countries in Latin America, such as Mexico, Peru, Colombia, and Puerto Rico, countries with Amerindian ancestral contributions that are heterogeneous among them, due to the different historical aspects of their formations and their degree of genetic mixing, which can explain the distance we found [11,28-30].

The identification of genetic variants associated with autism in the Amerindian population may favor the development of specific screening and diagnosis tools for this population, as well as for the Brazilian population and admixed populations, which have an important contribution of Amerindian ancestry in their constitution.

\section{Conclusions}

Our study was the first to investigate genes associated with autism in the Amazonian Amerindian, an understudied population that has a unique genetic profile. Our findings identify and characterized ASD-related SNPs, which could facilitate early disease testing and diagnosis, as well as early intervention in the Amerindian population and admixture populations with high contribution of Amerindian ancestry. This study may help better understand the biological mechanisms involved in the development of autism.

Supplementary Materials: The following supporting information can be downloaded at: https:// www.mdpi.com/article/10.3390/genes13020368/s1. Table S1: Description of all variants in the CHD8, SCN2A, FOXP1, and SYNGAP1 genes found in the Amerindian individuals (IND) Table S2: Pairwise FST among Amerindians (IND) and the five continental populations from the 1000 Genomes Project.

Author Contributions: Conceptualization, G.E.d.C. and G.L.F.; methodology, J.C.G.R.; software, L.F.P.; formal analysis, J.C.G.R.; investigation, G.E.d.C. and G.L.F.; resources, J.F.G.; writing—original draft preparation, G.E.d.C. and G.L.F.; writing-review and editing, G.E.d.C., G.L.F., E.E.B.P., D.F.d.V.B.L., M.R.F. and N.P.C.d.S.; supervision, N.P.C.d.S., S.E.B.d.S. and M.R.F.; project 
administration, R.M.R.B., P.P.A., J.F.G. and N.P.C.d.S.; funding acquisition, J.F.G. All authors have read and agreed to the published version of the manuscript.

Funding: This research was funded by Conselho Nacional de Desenvolvimento Científico e Tecnológico-CNPq (http: / / www.cnpq.br, accessed on October 2021); Coordenação de Aperfeiçoamento de Pessoal de Nível Superior (CAPES) (https: / / www.gov.br/capes / pt-br, accessed on October 2021); Pró-Reitoria de Pesquisa e Pós-Graduação da UFPA-PROPESP (http:/ / www.propesp.ufpa.br, accessed on October 2021) and Fundação Amazônia de Amparo a Estudos e Pesquisas-FAPESPA (http:/ / www.fapespa.pa.gov.br, accessed on October 2021). This work is part of the Rede de Pesquisa em Genômica Populacional Humana (Biocomputacional-Protocol no. 3381/2013/CAPES).

Institutional Review Board Statement: The study was conducted in accordance with the guidelines of the Declaration of Helsinki, and approved by Ethics Committee of the by the National Committee for Ethics in Research (CONEP) and the Research Ethics Committee of the UFPA Tropical Medicine Center (CAAE number: 20654313.6.0000.5172).

Informed Consent Statement: All participants of the study and their ethnic group leaders signed a free-informed consent.

Data Availability Statement: The dataset used in this study is publicly available. The name of the repository and accession number(s) can be found at https:/ / doi.org/10.6084/m9.figshare.18822272, accessed on October 2021.

Acknowledgments: We thank Núcleo de Pesquisas em Oncologia-NPO and Laboratório de Genética Humana e Médica-LGHM for technical support.

Conflicts of Interest: The authors declare no conflict of interest. The funders had no role in the design of the study; in the collection, analyses, or interpretation of data; in the writing of the manuscript; or in the decision to publish the results.

\section{References}

1. American Psychiatric Association. Diagnostic and Statistical Manual of Mental Disorders, 5th ed.; American Psychiatric Association: Washington, DC, USA, 2013.

2. Transtorno Do Espectro Autista-OPAS/OMS I Organização Pan-Americana da Saúde. Available online: https://www.paho. $\mathrm{org} / \mathrm{pt} /$ topicos/transtorno-do-espectro-autista (accessed on 1 September 2021).

3. Elsabbagh, M.; Divan, G.; Koh, Y.-J.; Kim, Y.S.; Kauchali, S.; Marcín, C.; Montiel-Nava, C.; Patel, V.; Paula, C.S.; Wang, C.; et al. Global Prevalence of Autism and Other Pervasive Developmental Disorders. Autism Res. 2012, 5, 160-179. [CrossRef] [PubMed]

4. Bailey, B.; Arciuli, J. Indigenous Australians with Autism: A Scoping Review. Autism 2020, 24, 1031-1046. [CrossRef] [PubMed]

5. Baron-Cohen, S. Leo Kanner, Hans Asperger, and the Discovery of Autism. Lancet 2015, 386, 1329-1330. [CrossRef]

6. Kanner, L. Autistic Disturbances of Affective Contact. Nerv. Child 1943, 2, 217-250.

7. Silberman, S.; Sacks, O. NeuroTribes the Legacy of Autism and How to Think Smarter about People Who Think Differently; Allen \& Unwin: London, UK, 2015.

8. Bai, D.; Yip, B.H.K.; Windham, G.C.; Sourander, A.; Francis, R.; Yoffe, R.; Glasson, E.; Mahjani, B.; Suominen, A.; Leonard, H.; et al. Association of Genetic and Environmental Factors with Autism in a 5-Country Cohort. JAMA Psychiatry 2019, 76, $1035-1043$. [CrossRef] [PubMed]

9. Sharma, S.R.; Gonda, X.; Tarazi, F.I. Autism Spectrum Disorder: Classification, Diagnosis and Therapy. Pharmacol. Ther. 2018, 190, 91-104. [CrossRef]

10. Satterstrom, F.K.; Kosmicki, J.A.; Wang, J.; Breen, M.S.; De Rubeis, S.; An, J.-Y.; Peng, M.; Collins, R.; Grove, J.; Klei, L.; et al. Large-Scale Exome Sequencing Study Implicates Both Developmental and Functional Changes in the Neurobiology of Autism. Cell 2020, 180, 568-584.e23. [CrossRef]

11. The 1000 Genomes Project Consortium. A Global Reference for Human Genetic Variation. Nature 2015, 526, 68-74. [CrossRef]

12. Sambrook, J.; Fritsch, E.F.; Maniatis, T. Molecular Cloning. 1; Cold Spring Harbor Laboratory Press: Cold Spring Harbor, NY, USA, 1989.

13. Rodrigues, J.C.G.; Fernandes, M.R.; Guerreiro, J.F.; da Silva, A.L.D.C.; Ribeiro-Dos-Santos, Â.; Santos, S.; Santos, N.P.C.D. Polymorphisms of ADME-Related Genes and Their Implications for Drug Safety and Efficacy in Amazonian Amerindians. Sci. Rep. 2019, 9, 7201. [CrossRef]

14. Maenner, M.J. Prevalence of Autism Spectrum Disorder among Children Aged 8 Years-Autism and Developmental Disabilities Monitoring Network, 11 Sites, United States, 2016. MMWR. Surveill. Summ. 2020, 69, 1-12. [CrossRef]

15. da Silva Montenegro, E.M.; Costa, C.S.; Campos, G.; Scliar, M.; de Almeida, T.F.; Zachi, E.C.; Silva, I.M.W.; Chan, A.J.S.; Zarrei, M.; Lourenço, N.C.V.; et al. Meta-Analyses Support Previous and Novel Autism Candidate Genes: Outcomes of an Unexplored Brazilian Cohort. Autism Res. Off. J. Int. Soc. Autism Res. 2020, 13, 199-206. [CrossRef] [PubMed] 
16. Shochet, I.M.; Orr, J.A.; Kelly, R.L.; Wurfl, A.M.; Saggers, B.R.; Carrington, S.B. Psychosocial Resources Developed and Trialled for Indigenous People with Autism Spectrum Disorder and Their Caregivers: A Systematic Review and Catalogue. Int. J. Equity Health 2020, 19, 1-19. [CrossRef] [PubMed]

17. Sandin, S.; Lichtenstein, P.; Kuja-Halkola, R.; Larsson, H.; Hultman, C.M.; Reichenberg, A. The Familial Risk of Autism. JAMA 2014, 311, 1770. [CrossRef] [PubMed]

18. Santos, N.P.C.; Ribeiro-Rodrigues, E.M.; Ribeiro-dos-Santos, Â.K.C.; Pereira, R.; Gusmão, L.; Amorim, A.; Guerreiro, J.F.; Zago, M.A.; Matte, C.; Hutz, M.H.; et al. Assessing Individual Interethnic Admixture and Population Substructure Using a 48-Insertion-Deletion (INSEL) Ancestry-Informative Marker (AIM) Panel. Hum. Mutat. 2010, 31, 184-190. [CrossRef] [PubMed]

19. Rodrigues de Moura, R.; Coelho, A.V.C.; de Queiroz Balbino, V.; Crovella, S.; Brandão, L.A.C. Meta-Analysis of Brazilian Genetic Admixture and Comparison with Other Latin America Countries. Am. J. Hum. Biol. 2015, 27, 674-680. [CrossRef] [PubMed]

20. Alotaibi, M.; Ramzan, K. A de Novo Variant of CHD8 in a Patient with Autism Spectrum Disorder. Discoveries 2020, 8, e107. [CrossRef]

21. Hoffmann, A.; Spengler, D. Chromatin Remodeler CHD8 in Autism and Brain Development. J. Clin. Med. 2021, 10, 366. [CrossRef]

22. Tavassoli, T.; Kolevzon, A.; Wang, A.T.; Curchack-Lichtin, J.; Halpern, D.; Schwartz, L.; Soffes, S.; Bush, L.; Grodberg, D.; Cai, G.; et al. De Novo SCN2A Splice Site Mutation in a Boy with Autism Spectrum Disorder. BMC Med. Genet. 2014, 15, 1-8. [CrossRef]

23. Varghese, M.; Keshav, N.; Jacot-Descombes, S.; Warda, T.; Wicinski, B.; Dickstein, D.L.; Harony-Nicolas, H.; De Rubeis, S.; Drapeau, E.; Buxbaum, J.D.; et al. Autism Spectrum Disorder: Neuropathology and Animal Models. Acta Neuropathol. 2017, 134, 537-566. [CrossRef]

24. Bowers, J.M.; Konopka, G. The Role of the FOXP Family of Transcription Factors in ASD. Dis. Mark. 2012, 33, 251-260. [CrossRef]

25. Siper, P.M.; De Rubeis, S.; Trelles, M.d.P.; Durkin, A.; Di Marino, D.; Muratet, F.; Frank, Y.; Lozano, R.; Eichler, E.E.; Kelly, M.; et al. Prospective Investigation of FOXP1 Syndrome. Mol. Autism 2017, 8, 1-16. [CrossRef] [PubMed]

26. Skoglund, P.; Reich, D. A Genomic View of the Peopling of the Americas. Curr. Opin. Genet. Dev. 2016, 41, 27-35. [CrossRef] [PubMed]

27. Hoffecker, J.F.; Elias, S.A.; O'Rourke, D.H.; Scott, G.R.; Bigelow, N.H. Beringia and the Global Dispersal of Modern Humans. Evol. Anthropol. Issues News Rev. 2016, 25, 64-78. [CrossRef] [PubMed]

28. Reich, D.; Patterson, N.; Campbell, D.; Tandon, A.; Mazieres, S.; Ray, N.; Parra, M.V.; Rojas, W.; Duque, C.; Mesa, N.; et al. Reconstructing Native American Population History. Nature 2012, 488, 370-374. [CrossRef]

29. Gravel, S.; Zakharia, F.; Moreno-Estrada, A.; Byrnes, J.K.; Muzzio, M.; Rodriguez-Flores, J.L.; Kenny, E.E.; Gignoux, C.R.; Maples, B.K.; Guiblet, W.; et al. Reconstructing Native American Migrations from Whole-Genome and Whole-Exome Data. PLoS Genet. 2013, 9, e1004023. [CrossRef]

30. Rodrigues, J.C.G.; Souza, T.P.D.; Pastana, L.F.; Ribeiro Dos Santos, A.M.; Fernandes, M.R.; Pinto, P.; Wanderley, A.V.; Souza, S.J.D.; Kroll, J.E.; Pereira, A.L.; et al. Identification of NUDT15 Gene Variants in Amazonian Amerindians and Admixed Individuals from Northern Brazil. PLoS ONE 2020, 15, e0231651. [CrossRef] 